Different Points of the Circulation in the Child and the Adult is compared by Dr. Leonard Findlay, who concludes that during childhood and youth the systolic arterial pressure is fairly uniform at different points of the circulation. In adult life the peripheral systolic pressure is lower than the central, and the difference between them increases with age. Finally, the difference greater than normal between the central and peripheral systolic pressures in cases of hypertension, from disease or experimentally produced, supports the idea that the behaviour of the pressure and its variations depend upon changes in the elasticity of the vessel wall. Dr. Peter F. Holst and Dr. A. H. Monrad-Krohn report two cases as a contribution to the study of the function of the $A .-V$. bundle. Dr. W. Hale White reports five cases of Fissential Renal Hæmaturia, which have been followed for much longer periods than almost all other published cases, with the moral that the outlook is good and that the disease does no harm apart from the loss of blood. In a critical review of the Crse of Tuberculin in So-called Tubercalous Glands, Dr. George E. Waugh concludes that any estimate of the value of injections of tuberculin in the treatment of enlarged glands must be invalidated by the fact that no proof that the glands were tuberculous can be offered until the glands have been subjected to operation. The most important factor in the treatment of chronic glandular enlargement with a view to the avoidance of extensive operative interference is the complete elimination of all primary foci of infection. The use of the guillotine in the tonsils is one of the most serious causes of failure in the treatment of enlarged glands. Wright's bacillary emulsion thas not been proved to be of any value, though it is probably harmless. In enlarged glands which on removal proved to be tuberculous, thickening of the operation scar frequently occurred, but disappeared under a course of injections of tuberculin.

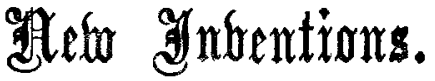

\section{NEW OPHTHALMIC CALIPERS.}

WITH the increasing necessity for the correct centring of spectacles there comes the demand for a rapid and accurate measurement of the ocular base line. It is no longer found sufficient, as in former days, to take a rough measurement of the interpupillary distance. The instrument shown in the accompanying illustration was devised for the purpose of

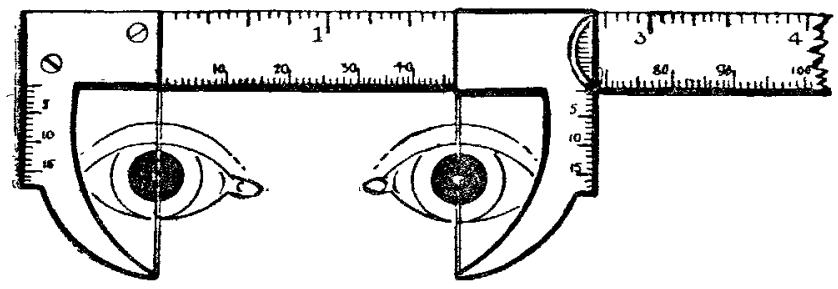

measuring the base line in working with the registering form of diaphragm test, and the new calipers have proved, after a year's work, to give this measurement with the greatest expedition and with an accuracy that meets the stringent conditions of that test for binocular vision. In experimental forms these calipers were exhibited to the Ophthalmological Society in 1909 and 1910; they are now made by Messrs. G. Culver. Limited. The raw material used is steel, and the workmanship is excellent. Briefly the method of usage is as follows. The patient faces a distant light, either a window or lamp, and looks at it with both eyes; the images of the light are seen upon the cornex and mark the visual axes. The surgeon faces the patient at arm's length, places the rule upon the patient's brows, and sights the fixed wire over the image on the patient's right eye. Then the other wire is slid over the image on the left cornea and carefully sighted. The surgeon sights the patient's right eye with his own left eye and rive versa. In measuring the base line for near vision the procedure is the same, but the light is put over the surgeon's head at the requisite distance and the patient looks at it. The vertical scales on the jaws are for the purpose of measuring the vertical displacement of lenses for the correction of byperphoria. The trial lenses are tilted until the defect as measured with the scale test card in the diaphragm test is corrected, the rule is held horizontally across the patient's brows, and the depression of the lens of one side as compared with the other read off.

Harley-street, W.

N. Bishop Harman, F.R.C.S. Eng.

\section{A BALANOE-WEIGHT FOR THE CLINICAL POLYGRAPH.}

PRoB ABLY not a few beginners with the clinical polygraph have found among their other troubles a difficulty in keeping the spring of the sphygmograph in contact with the radial artery when the "arm "carrying the tambour for collecting the pulsations from the neck is placed in situ. The weight of this is apt, more especially in the case of slender wrists, to tilt the sphygmograph outwards, and thus to remove the instrument from the artery and to cause the loss of the radial tracing. If, in order to avoid such a result, the wriststrap of the sphygmograph is drawn more tightly, the consequences are unpleasant for the patient, and the undue pressure thus occasioned may, once again, diminish or suppress the arterial excursion. After various attempts to get rid of this annoyance $I$ have at last hit upon a simple mechanical contrivance which may perhaps

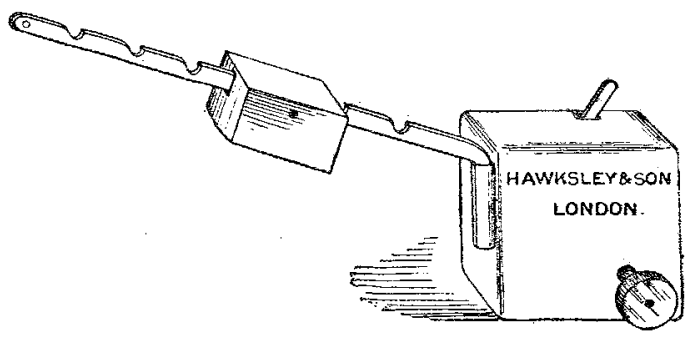

be of service to other workers. The principle of it is the provision of a weight in opposition to the force or leverage exercised by the "neck tambour" and by the "arm "which carries this tambour, and this in such a fashion as to allow graduation of the balancing or resisting force without altering the amount of pressure exerted on the radial artery by the spring and pad of the sphygmograph. To secure these ends a socket is fixed on that side of the box containing the clockwork of the sphygmograph opposite to the one carrying the tambour "arm," and into this socket is fitted an angled rod carrying a moveable weight and notehed so as to allow the weight to be temporarily adjusted at different points, the arrangement being, in short, similar to a steelyard. If after the sphygmograph has been attached to the wrist the tambour arm and the balance weight are placed in position the whole apparatus remains perfectly steady, and thus the inscription of the two tracings is much facilitated. The balance-weight is readily added to the present pattern of Dr. Mackenzie's clinical polygraph, and is not without value, at least in occasional instances, in the use of the sphygmograph pure and simple. It bas been made for me by Hawksley and Son, 357, Oxford-street, W.
Harley-street, W.
C. O. HAWTHORNE, M.D. Glasg.

International Monument to Cesare LomBROSO. - The central committee in Rome charged with the carrying out of this undertaking has just received the sum of $\& 62$ from the Scottish committee organised with the same object under the presidency of Lord Guthrie, one of the judges of the Conrt of Session. The central committee also announces contributions to the movement from continental committees whose interest in the founder of the science of "criminal anthropolngy" seems proportioned to the recrudescence of " hooliganism," represented abroad by the "apaches" of France, the "teppisti" of Italy, and the "Mano Nera" of the United States. 


\section{THE LANCET.}

IIONDON: SATURDAY, SEPTEMBER 9, 1911.

\section{Inebriety and Alcoholism.}

LEGISLATIVE enactments, like individual enterprises, are apt occasionally to produce effects so different in their nature and influence from what their authors had promised and expected that it may be a matter of difficulty to recognise the original intention in the final result. The Inebriates Act of 1898 is a very striking instance of this sort of miscalculation. The object of the Act, as was generally understood when it was placed on the statute book, was to give effect to the view, which had been strongly voiced by medical opinion, that the pathological factor in inebriety ought to be considered in the treatment of inebriate offenders. Instead of regarding intemperance merely as a vice, which when it led to antisocial acts was if anything an aggravation of their iniquity and as such entailed a proportionately heavier penalty, the law now set itself to recognise that inebriety might be due to a condition of disease, the existence of which in a delinquent should take him out of the category of ordinary criminals and should bring him under curative treatment rather than penal discipline. Unfortunately, however, in framing the measure which was to embody this very sound view the legislature thought fit to adopt a plan which appears to have been inspired by totally different and quite incompatible principles. Though proceeding, as we have seen, from the assumption that the condition to be dealt with was one of disease, it rigorously reserved to the administrators of the law not only the prescription of the treatment but also the making of the diagnosis. So strictly, indeed, has this singular system been adhered to that, though a medical certificate is required as part of the machinery for committal to an inebriate reformatory, the official form on which it has to be furnished omits all reference to the patient's inebriety; the certifying physician is invited to express an opinion as to the intemperance of the patient's grandmother, but the intemperance of the patient does not concern him and is wholly a matter for the superior diagnostic skill of the police. It was hardly to be anticipated that the results attained by these very novel methods would be of a kind to encourage further experiments on similar lines. And that they are most distinctly not of such a kind is made abundantly clear in the very interesting but rather pessimistic report of Dr. R. W. BRANTHWAITE on the working of the Inebriates Acts (1879 to 1900) during the year 1909, which has just been published.
Dr. BRANThwaIte, whose annual reports are usually distinguished by a freshness of idea and a carefal style not too common in blue-books, has devoted the greater part of his latest volume to a general disquisition on the nature of inebriety and the characteristics of the inebriate. In this connexion, of course, it has to be remembered that these terms are used in a somewhat special sense determined by the very peculiar legislation which has provided the material for Dr. BRANTHwaite's words. Thus, what we are to understand by an inebriate in this report is simply an inmate of an inebriate reformatory, and inebriety in the same way can hardly be defined wore exactly than as a liability to become such an inmate. It will be seen from this that Dr. BRANTHWAITE's description of the condition in question and of its victims suffers under the disadvantage that he has had to seek out biological and psycho. logical characters in a category of individuals defined by a purely legal criterion, and a very roughand-ready one at that. His task, in fact, is somewhat like that of a naturalist who should be called on to furnish a scientific description of the horse, the horse being first defined inclusively and exclusively as any animal found in a stable. It is necessary to point this out, because Dr. BRANTHWAITE does not appear to have indicated it with quite sufficient clearness, and the unwary reader might easily fall into the error of supposing that the report purported to give an account of alcoholism and alcoholic subjects in the medical sense, and not simply a description of the sort of individuals who get committed to inebriate reformatories under the existing law. Such a misapprehension of its real purport would be the more regrettable because it would interfere with the due appreciation of the lesson which this valuable report can teach regarding the defects and limitations of the Inebriates Act of 1898. For it may be safely affirmed that the fact most clearly brought out by Dr. Branthivaite's inquiry - and the fact, we may add, of most practical importance-is the complete failure of that Act to touch even the fringe of the problem of chronic alcoholism. The evidences of this are manifold. In the first place, we have the fact that of the total number of "inebriates" committed to reformatories during the last ten years-3309 in all-only 542 , or 16 per cent., were men, although, as is well known, the incidence of chronic alcoholism, as measured, for instance, by the mortality from delirium tremens and other manifestations of chronic intoxication, is far higher in men than in women. Again, we observe that in only 9 per cent. of the reformatory patients is even a probable history of delirium tremens forthcoming, and this despite the inclusion of several doubtful cases. F arther, we learn that it is rare to find any evidence of permanent tissue change resulting from alcoholic excess in these individuals ; and, again, that they display a "conspicuous absence of disease of the intestinal tract, disease of the kidneys, and gout."

These latter facts lead Dr. BRANTHWaIte to express some doubt as to the soundness of current medical teaching which attributes many organic and functional disorders to the action of alcohol taken in excess, but unless we are to adopt the same attitude of scepticism with regard to the general belief in the alcoholic origin of 